\title{
The effect of bipolar I disorder and major depressive disorder on workforce function
}

RS McIntyre, MD, FRCPC (1,2,3); K Wilkins, MSc. (4); H Gilmour, MA (4); JK Soczynska, HBSc. (3,5);

JZ Konarksi, MSC. (4); A Miranda (3); HO Woldeyohannes, HBSC. (3); D Vagic, MD (3); M Alsuwaidan, MD (1);

SH Kennedy, MD, FRCPC $(1,3,5)$

\begin{abstract}
This investigation was undertaken to explore and compare the effect of bipolar I disorder $(B D)$ and major depressive disorder (MDD) on workforce function. The data for this analysis were procured from the Canadian Community Health Survey (CCHS 1.2). The sample consisted of 20747 individuals ( $\geq 18$ years old and currently working); the proportions screening positive for lifetime $B D$ and $M D D$ were $2.4 \%$ and $11.2 \%$, respectively. Individuals with $B D$ or $M D D$ had a significantly lower mean annual income, compared to people without these disorders. Individuals with $B D$ had a significantly lower annual income when compared to MDD ( $\mathrm{p}<0.05)$. Results from a multiple logistic regression also indicate that employed individuals with $B D$ had greater odds of reporting one or more mental health disability days in the past two weeks, compared with those with $M D D(O R=1.6 ; 95 \% C I=1.0$ to 2.6). Currently employed individuals with $B D$ had lower odds of "good job security" relative to those with $M D D(O R=0.695 \% C I=$ 0.5 to 0.9). The data herein underscore the pernicious effect of $B D$ on workforce function, and suggest that opportunistic screening for $B D$ in all individuals utilizing employment assistance programs for depression might be warranted.
\end{abstract}

Key words: bipolar disorder, major depressive disorder, workforce function, human capital

\section{Introduction}

Mounting evidence indicates that mood disorders are a leading cause of disability and premature mortality. ${ }^{(1,2)}$ Cost-of-illness studies indicate that mood disorders impart staggering direct and indirect costs in both developed and developing nations. ${ }^{(3)}$ Decrements in workforce productivity comprise a significant component of the overall cost of illness. ${ }^{(4)}$ Improved recognition and management of mood disorders have important implications for averting expenditures and reducing cost. ${ }^{(5)}$

Most cost-of-illness studies focus on individuals diagnosed with major depressive disorder (MDD) with relatively fewer studies separately evaluating the effect of bipolar disorder (BD). ${ }^{(6-8)}$ During the past decade, the estimated lifetime prevalence of $\mathrm{BD}$ has increased considerably largely due to the broadening diagnostic boundaries. ${ }^{(9)}$ Taken together, the total cost of mood disorders attributable to $\mathrm{BD}$ may be considerably higher than previously estimated. ${ }^{(6,10)}$

The only study to present comparative information on the workforce costs of MDD and $\mathrm{BD}$ reported that BD was associated with more lost work days per ill worker per year. ${ }^{(4)}$ This effect was mediated by greater severity and persistence of depressive symptoms in BD versus MDD. It was also reported that presenteeism (i.e., low performance while at work) accounted for approximately two-thirds of the total workforce cost of illness.

This investigation was undertaken to describe and compare the effect of $\mathrm{BD}$, relative to MDD and the general population, on workforce function. The data for this post hoc analysis was from a Canadian crossnational mental health survey.

\section{Methods}

The data for this analysis were procured from the 2002 Canadian Community Health Survey: Mental Health and Well-being (82-617-XIE); a component of the Canadian Community Health Survey (CCHS), conducted by Statistics Canada. Information about the survey is available at http://www.statcan.ca:8096/ bsolc/english/bsolc? catno $=82-617-\mathrm{X}$.

\section{Author References}

1 Department of Psychiatry, University of Toronto, Toronto, ON

2 Department of Pharmacology, University of Toronto, Toronto, ON

3 Mood Disorders Psychopharmacology Unit, University Health Network, Toronto, ON

4 Health Statistics Division, Statistics Canada, Ottawa, ON

5 Institute of Medical Science, University of Toronto, Toronto, ON

Correspondence: Dr. Roger S. McIntyre, MD, FRCPC, Associate Professor, Department of Psychiatry and Pharmacology, University of Toronto; Head, Mood

Disorders, Psychopharmacology Unit, University Health Network, 399 Bathurst Street, Toronto, ON, Canada M5T 2S8, Tel: (416) 603-5279, Fax: (416) 603-5368,

Email: roger.mcintyre@uhn.on.ca 
The survey employed the World Health Organization (WHO) World Mental Health 2000 version of the Composite International Diagnostic Interview (WMHCIDI). The questionnaire used can be found at http://www.statcan.ca/english/ sdds/instrument/5015_Q1_V1_E.pdf .

Respondents were residents of private dwellings; a multistage stratified cluster design was used to sample dwellings. Most interviews (86\%) were conducted in person; the remainder by telephone. The responding sample totaled 36984 people aged 15 or older; the participation rate was high $(77 \%)$. The data were weighted to be representative of the household population of the ten provinces of Canada in 2002. The analysis herein was limited to individuals aged 18 or older and currently working.

The CCHS collected information on determinants and correlates of mental health such as socio-demographics, income, self-reported distress, level of leisuretime physical activity, medication use, and social support. Based on WHM-CIDI screening criteria, the survey collected information on lifetime and past 12-month prevalence of various mental disorders and behaviours (i.e. major depressive episode, manic episode, panic disorder, agoraphobia, social phobia, alcohol and drug dependence, gambling, suicide, and abnormal eating behavior), self-reported height and weight, and previously diagnosed medical disorders. Work-related variables included current employment status, self-perceived job security and the number of "mental health disability days" experienced in the past two weeks. The latter variable was measured by asking respondents if, in the past 2 weeks, they had "stayed in bed all or most of day or cut down on activities because of illness or injury," or had days that "took extra effort to perform up to their usual level at work or in other daily activities due to emotional or mental health or use of alcohol or drugs."
Statistical analyses were calculated by producing frequencies, cross-tabulations and multiple regression models. All analyses were based on data weighted to be representative of the Canadian population aged 18 or older in 2002. Based on data for those screened positive for lifetime mood disorder (bipolar I or depression), multiple logistic regression modeling was used to compare the associations of lifetime bipolar I disorder and lifetime depressive disorder with self-reported job security, and with mental health disability days in the past two weeks. For the analysis, mutually exclusive groups were created as follows: persons screened positive for lifetime bipolar I disorder (BD); persons screened positive for lifetime major depressive disorder (without bipolar I disorder) (MDD); and persons with neither mood disorder.

The models controlled for the effects of sex, age group, level of education, presence of physician-diagnosed chronic medical disorders (arthritis, asthma, back problems excluding fibromyalgia and arthritis, high blood pressure, migraine, chronic bronchitis, emphysema or chronic obstructive pulmonary disease, diabetes, epilepsy, heart disease, cancer, stomach or intestinal ulcers, effects of a stroke, bowel disorder/Crohn's disease or colitis, Alzheimer's disease or other dementia, cataracts, glaucoma, and thyroid disorder) and body mass index. Preliminary analysis revealed a relatively high prevalence of substance (alcohol or illicit drugs) dependency in persons with BD or MDD. Twelve-month dependency estimates were $23 \%$ and $7 \%$, respectively, compared with $3 \%$ in the general population (data not shown). Therefore, to avoid multicollinearity, no variable for substance dependency was included in the multivariate regression models.

All statistical analyses were performed using SAS statistical software, release 9.1 (SAS Institute, Cary, NC). Variables for analysis were selected a priori, based on previous research. To account for the complex sampling design of the CCHS, coefficients of variation on estimates and significance of differences between estimates were calculated using the bootstrap technique. The level of statistical significance was defined as $p<0.05$.

\section{Results}

A positive screen for a lifetime manic episode (i.e. DSM-IV-defined bipolar I disorder) was ascertained in an estimated $2.4 \%$ of the currently employed Canadian population aged 18 or older. Lifetime history of BD was more frequent in younger respondents, in persons not married or living with a partner, and in those with incomplete post-secondary education (Table 1). The proportion of the employed population aged 18 or older with a positive screen for lifetime MDD (without BD) was estimated at $11.2 \%$.

Among Canadians aged 18 or older in 2002, the proportion of people who were currently employed did not differ significantly according to the presence of lifetime mood disorder, nor did it differ between persons with lifetime $\mathrm{BD}$ and those with lifetime MDD. In persons with no history of mood disorder, $70 \%$ were employed; the proportion in those with BD was $68 \%$, and in those with MDD, $69 \%$ reported employment at the time of the survey (data not shown). In all three groups, most individuals who were employed had full-time jobs $(86 \%$ in those with no mood disorder; $87 \%$ in those with lifetime $\mathrm{BD} ; 84 \%$ in those with lifetime MDD; the differences between proportions were not statistically significant) (data not shown).

The mean annual income of employed persons with mood disorder was substantially lower than that for those who were unaffected. Persons with lifetime BD had an average income of $\$ 32,000$-nearly 
$\$ 5,000$ less than the average income $(\$ 36,800)$ of those with MDD $(p<0.05)$ (Table 2). For persons with neither mood disorder, the average yearly income was $\$ 40,300$ - substantially and statistically higher than that of either of the mood disorder groups $(p<0.05)$.
The results of multivariate modeling indicated that the odds of having experienced at least one mental health disability day within the past two weeks was significantly higher in persons with lifetime $\mathrm{BD}(\mathrm{OR}=8.8$; $95 \% \mathrm{CI}=5.9$ to 13.1 ) or lifetime MDD $(\mathrm{OR}=5.6 ; 95 \% \mathrm{CI}=4.1$ to 7.7$)$, compared with the odds for persons with neither disorder (Table 3a). In comparison with persons with lifetime MDD, those with lifetime BD had significantly higher odds of having experienced at least one mental health disability day within the past two weeks $(\mathrm{OR}=1.6 ; 95 \% \mathrm{CI}=1.0$ to 2.6$)$

TABLE 1

Prevalence of lifetime bipolar I disorder (BD) and major depressive disorder (MDD) (excluding BD) by selected sociodemographic characteristics, employed household population aged 18 or older, Canada excluding territories, 2002

\begin{tabular}{|c|c|c|c|c|c|c|}
\hline & \multicolumn{2}{|c|}{ Lifetime BD } & \multicolumn{2}{|c|}{ Lifetime MDD (excl. BD) } & \multicolumn{2}{|c|}{$\begin{array}{l}\text { Neither lifetime BD } \\
\text { nor lifetime MDD }\end{array}$} \\
\hline & Est'd number & $\%$ & Est'd number & $\%$ & Est'd number & $\%$ \\
\hline \multicolumn{7}{|l|}{ Sex } \\
\hline Males $^{+}$ & 207000 & 2.5 & 677000 & 8.1 & 7506000 & 89.5 \\
\hline 18 to 34 & 146000 & $2.8^{*}$ & 529000 & $10.0^{*}$ & 4592000 & 87.2 \\
\hline $35+^{+}$ & 225000 & 2.2 & 1208000 & 11.9 & 8728000 & 85.9 \\
\hline \multicolumn{7}{|l|}{ Level of education } \\
\hline Secondary graduation or less & 140000 & 2.6 & 512000 & $9.7^{*}$ & 4628000 & 87.6 \\
\hline Married/living with partner ${ }^{\dagger}$ & 177000 & 1.7 & 1503000 & 10.1 & 9195000 & 88.2 \\
\hline Separated/divorced/widowed & 77000 & $5.7^{*}$ & 293000 & $21.4^{*}$ & 997000 & $72.9^{*}$ \\
\hline Never married & 117000 & $3.2^{*}$ & 390000 & 10.8 & 3110000 & 86.0 \\
\hline
\end{tabular}

${ }^{\dagger}$ Reference group.

* Estimate is significantly different from estimate for reference category $(p<0.05)$.

Because of rounding and data not available (level of education), detail does not always sum to total.

Source: 2002 Canadian Community Health Survey: Mental Health and Well-being.

TABLE 2

Mean annual income, by presence of mood disorder (lifetime bipolar I disorder (BD) or major depressive disorder (MDD)), employed household population aged 18 or older, Canada excluding territories, 2002

\begin{tabular}{lc}
\hline Disorder & Mean income (C\$) \\
\hline Lifetime BD & $32,000^{*}$ \\
Lifetime MDD (excluding BD) & 36,800 \\
General population without mood disorder & 40,300 \\
\hline * Estimate is significantly lower than estimates for other categories ( $p<0.05)$ \\
Source: 2002 Canadian Community Health Survey: Mental Health and Well-being.
\end{tabular}


TABLE 3a

Adjusted odds ratios for one or more mental health disability days in past two weeks in relation to presence of mood disorder

(lifetime bipolar I disorder (BD) or lifetime major depressive disorder (MDD)), controlling for selected characteristics, currently employed household population aged 18 or older, Canada excluding territories, 2002

\begin{tabular}{|c|c|c|}
\hline & Odds ratio & $\mathbf{9 5} \%$ confidence interval \\
\hline \multicolumn{3}{|l|}{ Mood disorder } \\
\hline Lifetime BD & $8.8^{*}$ & 5.9 to 13.1 \\
\hline Lifetime MDD (excluding BD) & $5.6^{*}$ & 4.1 to 7.7 \\
\hline None $^{\dagger}$ & 1.0 & - \\
\hline \multicolumn{3}{|l|}{ Sex } \\
\hline Males & 0.8 & 0.6 to 1.0 \\
\hline Females $^{\dagger}$ & 1.0 & - \\
\hline \multicolumn{3}{|l|}{ Age group } \\
\hline 18 to 34 & $1.6^{*}$ & 1.2 to 2.1 \\
\hline $35+^{+}$ & 1.0 & - \\
\hline \multicolumn{3}{|l|}{ Level of education } \\
\hline High school graduation or less ${ }^{\dagger}$ & 1.0 & - \\
\hline Some post-secondary education & 0.8 & 0.5 to 1.3 \\
\hline Post-secondary graduation & $0.7^{*}$ & 0.5 to 1.0 \\
\hline \multicolumn{3}{|l|}{ Comorbidity } \\
\hline Chronic condition present ${ }^{\S}$ & $2.0^{*}$ & 1.5 to 2.8 \\
\hline \multicolumn{3}{|l|}{ Body mass index category } \\
\hline $\begin{array}{l}\text { Underweight/normal weight/ } \\
\text { overweight }(\mathrm{BMI}<30.0)^{\dagger}\end{array}$ & 1.0 & - \\
\hline Obese (BMI 30.0+) & 0.8 & 0.5 to 1.1 \\
\hline
\end{tabular}

* Estimate is significantly different from estimate for reference category $(p<0.05)$

+ Reference group, for which the odds ratio is always 1.0

- Not applicable

$\S$ Reference group is absence of arthritis, asthma, back problems excluding fibromyalgia and arthritis, high blood pressure, migraine, chronic bronchitis, emphysema or COPD, diabetes, epilepsy, heart disease, cancer, stomach or intestinal ulcers, effects of a stroke, bowel disorder/Crohn's disease or colitis, Alzheimer's disease or other dementia, cataracts, glaucoma, and thyroid disorder.

Odds ratios have been rounded; some with 1.0 as the lower or upper confidence limit are statistically significant (as indicated).

Model is based on records of 20431 respondents.

Source: 2002 Canadian Community Health Survey: Mental Health and Well-being.
(Table 3b). Similarly, the odds of reporting good job security were significantly lower in persons with $\mathrm{BD}(\mathrm{OR}=0.4 ; 95 \%$ $\mathrm{CI}=0.3$ to 0.6$)$ or $\mathrm{MDD}(\mathrm{OR}=0.7 ; 95 \%$ $\mathrm{CI}=0.6$ to 0.8$)$ than in persons without either mood disorder (Table 4a). As well, those with $\mathrm{BD}(\mathrm{OR}=0.6 ; 95 \% \mathrm{CI}=0.5$ to 0.9) compared unfavorably to those with MDD (Table 4b). These associations were present after controlling for the effects of the potentially confounding influences of sex, age group, level of education, medical comorbidity and body mass index category.

\section{Discussion}

These results suggest that, on several indices of workforce function, individuals with either BD or MDD are strikingly more impaired than persons without mood disorder. These data further suggest that individuals with BD may be more impaired than individuals with MDD as evinced by annual income, more mental health disability days, and job security.

The only other investigation to present comparative information on the workforce costs of MDD and BD also reported that mood disorders predicted overall lost work performance with an estimated 65.5 lost workdays per worker with $\mathrm{BD}$ and 27.2 lost workdays per worker with MDD. ${ }^{(4)} \mathrm{No}$ significant differences in the association of $\mathrm{BD}$ and MDD with work performance were found by sex or age. Work loss associated with BD affected all occupational groups with a significantly greater effect noted among technical and professional workers in the case of absenteeism and among laborers and professional workers in the case of presenteeism. 
During the past decade, several observations in mood disorders provide a relevant context to workforce dysfunction studies. Firstly, the estimated lifetime prevalence of bipolar spectrum disorders is considerably higher than previously estimated. ${ }^{(9)}$ For example, it is now estimated that 2 to $5 \%$ of the general population may be affected by BD. ${ }^{(11,12)}$ In keeping with this view, the percentage of employable individuals with $\mathrm{BD}$ may be higher than previously estimated. Secondly, similar to MDD, the longitudinal symptomatic structure of $\mathrm{BD}$ is dominated by chronic subsyndromal depressive symptoms. ${ }^{(13-16)}$ It is increasingly recognized that depressive symptoms are a more impairing aspect of $\mathrm{BD}$ when compared to manic symptoms. ${ }^{(17)}$ Moreover, individuals with bipolar spectrum disorders (a predominantly depressive phenotype) exhibit impairment in functioning inter-mediate between those with bipolar I disorder and of non-cases in the general population. ${ }^{(9,18)}$ Thirdly, several cost-of-illness studies indicate that mood disorders are associated with substantial decrement in work performance, as well as appreciable caregiver burden, medical service utilization, and premature mortality. ${ }^{(1,7,19)}$ Improved recognition and management of non-bipolar depression has been shown to reduce overall illness burden and reduce costs. ${ }^{(20)}$

Several factors limit the interpretations and inferences that can be drawn from this analysis. The major limitation of this post hoc analysis is that the CCHS was not designed a priori to evaluate and compare the effects of mood disorders on workforce function. The CCHS did not have a specific
TABLE 3b

Adjusted odds ratios for one or more mental health disability days in past two weeks in relation to lifetime bipolar I disorder (BD) and lifetime major depressive disorder (MDD), controlling for selected characteristics, currently employed household population aged 18 or older with mood disorder, Canada excluding territories, 2002

\begin{tabular}{|c|c|c|}
\hline & Odds ratio & $95 \%$ confidence interval \\
\hline \multicolumn{3}{|l|}{ Mood disorder } \\
\hline Lifetime BD & $1.6^{*}$ & 1.0 to 2.6 \\
\hline Lifetime MDD ${ }^{\dagger}$ (excluding BD) & 1.0 & - \\
\hline \multicolumn{3}{|l|}{ Sex } \\
\hline Males & 0.9 & 0.5 to 1.4 \\
\hline Females $^{\dagger}$ & 1.0 & - \\
\hline \multicolumn{3}{|l|}{ Age group } \\
\hline 18 to 34 & 1.5 & 0.9 to 2.5 \\
\hline $35+^{+}$ & 1.0 & - \\
\hline \multicolumn{3}{|l|}{ Level of education } \\
\hline High school graduation or less ${ }^{\dagger}$ & 1.0 & - \\
\hline Some post-secondary education & $0.5^{*}$ & 0.2 to 1.0 \\
\hline Post-secondary graduation & $0.5^{*}$ & 0.3 to 0.8 \\
\hline \multicolumn{3}{|l|}{ Comorbidity } \\
\hline Chronic condition present ${ }^{\S}$ & $2.0^{*}$ & 1.2 to 3.3 \\
\hline \multicolumn{3}{|l|}{ Body mass index category } \\
\hline $\begin{array}{l}\text { Underweight/normal weight/ } \\
\text { overweight }(\mathrm{BMI}<30.0)^{\dagger}\end{array}$ & 1.0 & - \\
\hline Obese (BMI 30.0+) & 1.2 & 0.7 to 1.9 \\
\hline
\end{tabular}

* Estimate is significantly different from estimate for reference category $(p<0.05)$

${ }^{+}$Reference group, for which the odds ratio is always 1.0

- Not applicable

${ }^{\S}$ Reference group is absence of arthritis, asthma, back problems excluding fibromyalgia and arthritis, high blood pressure, migraine, chronic bronchitis, emphysema or COPD, diabetes, epilepsy, heart disease, cancer, stomach or intestinal ulcers, effects of a stroke, bowel disorder/Crohn's disease or colitis, Alzheimer's disease or other dementia, cataracts, glaucoma, and thyroid disorder.

Odds ratios have been rounded, some with 1.0 as the lower or upper confidence limit are statistically significant (as indicated).

Model is based on records of 2999 respondents screened positive for lifetime BD or MDD.

Source: 2002 Canadian Community Health Survey: Mental Health and Well-being 
TABLE 4a

Adjusted odds ratios for good job security in relation to presence of mood disorder (lifetime bipolar I disorder (BD) or lifetime major depressive disorder (MDD)), controlling for selected characteristics, currently employed household population aged 18 or older, Canada excluding territories, 2002

\begin{tabular}{|c|c|c|}
\hline & Odds ratio & 95\% confidence interval \\
\hline \multicolumn{3}{|l|}{ Mood disorder } \\
\hline Lifetime BD & $0.4^{*}$ & 0.3 to 0.6 \\
\hline Lifetime MDD (excluding BD) & $0.7^{*}$ & 0.6 to 0.8 \\
\hline None $^{+}$ & 1.0 & - \\
\hline \multicolumn{3}{|l|}{ Sex } \\
\hline Males & 1.0 & 0.9 to 1.1 \\
\hline Females $^{+}$ & 1.0 & - \\
\hline \multicolumn{3}{|l|}{ Age group } \\
\hline 18 to 34 & 1.0 & 0.9 to 1.1 \\
\hline $35+^{+}$ & 1.0 & - \\
\hline \multicolumn{3}{|l|}{ Level of education } \\
\hline High school graduation or less ${ }^{\dagger}$ & 1.0 & - \\
\hline Some post-secondary education & 0.9 & 0.8 to 1.1 \\
\hline Post-secondary graduation & $0.9^{*}$ & 0.8 to 1.0 \\
\hline \multicolumn{3}{|l|}{ Comorbidity } \\
\hline Chronic condition present ${ }^{\S}$ & 0.9 & 0.8 to 1.0 \\
\hline \multicolumn{3}{|l|}{ Body mass index category } \\
\hline $\begin{array}{l}\text { Underweight/normal weight/ } \\
\text { overweight }(\mathrm{BMI}<30.0)^{\dagger}\end{array}$ & 1.0 & - \\
\hline Obese (BMI 30.0+) & 1.0 & 0.9 to 1.2 \\
\hline
\end{tabular}

* Estimate is significantly different from estimate for reference category $(p<0.05)$

+ Reference group, for which the odds ratio is always 1.0

- Not applicable

$\S$ Reference group is absence of arthritis, asthma, back problems excluding fibromyalgia and arthritis, high blood pressure, migraine, chronic bronchitis, emphysema or COPD, diabetes, epilepsy, heart disease, cancer, stomach or intestinal ulcers, effects of a stroke, bowel disorder/Crohn's disease or colitis, Alzheimer's disease or other dementia, cataracts, glaucoma, and thyroid disorder.

Odds ratios have been rounded, some with 1.0 as the lower or upper confidence limit are statistically significant (as indicated).

Model is based on records of 20251 respondents.

Source: 2002 Canadian Community Health Survey: Mental Health and Well-being quantitative measure of work performance (e.g., World Health Organization Health and Work Performance Questionnaire). We are also unable to comment on components of impaired function and their contribution to overall performance and cost. For example, presenteeism may account for a larger component of workforce cost than absenteeism in the BD population. ${ }^{(4)}$ In keeping with this view, the CCHS does not have detailed longitudinal ratings of mood symptoms which prevents us from commenting on the relative contribution of depressive (or manic) symptoms to overall work performance. A symptomatic analysis of the comparative study by Kessler et al. indicates that the greater severity and persistence of depressive symptoms in the $\mathrm{BD}$ population mediates the greater effect of BD on workforce performance. The restriction of the study sample to persons currently employed also limits the interpretation of the results of the analysis. Specifically, any tendency for persons with BD or MDD to have disproportionately exited (or never entered) the labour force, relative to persons without these disorders, would result in diluting the strength of the observed association of mood disorder with work impairment from its true magnitude.

Other limitations of the CCHS include: diagnosis was based on the CIDI which is less able to distinguish mixed episodes and bipolar spectrum conditions from MDD;(21) insufficient information regarding prior work history and details of effects across different occupational groups; no objective measures of workforce performance; reliance on self-reporting for all dependent variables; the inclusion of persons whose manic episodes may have been due to 
substance abuse; and inability to control for the effect of treatment. As well, although previous versions of the CIDI have been validated for use in communitybased surveys, a version updated for the 2000 World Mental Health Initiative was used by the CCHS, and its validation has not been completed. Therefore, the extent to which assessments made by trained clinicians would correspond with CCHS findings is unknown. Nevertheless, individuals screening positive for MDD or $\mathrm{BD}$ in the CCHS survey are representative of other individuals with these disorders with respect to their lifetime prevalence, demographics, patterns of comorbidity, functional medical service utilization, and functional outcome. ${ }^{(22-24)}$

There is general awareness that mood disorders differentially affect disabled workers. ${ }^{(3)}$ The higher prevalence of MDD versus $\mathrm{BD}$ in the general population (and workforce) indicates that the aggregate cost of MDD is greater. ${ }^{(4)}$ Nevertheless, at an individual level, the study herein as well as the results from the Kessler et al. investigation, suggest that $\mathrm{BD}$ may be a more costly disorder. Emanating from this observation, screening and intervention programs for individuals with bipolar I disorder, and bipolar spectrum, may be more cost-effective than such programs for those with MDD. ${ }^{(8)}$ Behavioural health providers and employment assistance programs should incorporate opportunistic facile screening for BD.

\section{References}

1. Greenberg PE, Stiglin LE, Finkelstein SN, et al. The economic burden of depression in 1990. J Clin Psychiatry 1993 November;54(11):405-18.

2. McIntyre RS, Konarski JZ. Bipolar disorder: a national health concern. CNS Spectr 2004 December;9(11 Suppl 12):6-15.

3. Murray CJ, Lopez AD. Global mortality, disability, and the contribution of risk factors: Global Burden of Disease Study. Lancet 1997 May 17;349(9063):1436-42.

TABLE 4b

Adjusted odds ratios for good job security in relation to lifetime bipolar I disorder (BD) and lifetime major depressive disorder (MDD), controlling for selected characteristics, currently employed household population aged 18 or older with mood disorder, Canada excluding territories, 2002

\begin{tabular}{|c|c|c|}
\hline & Odds ratio & 95\% confidence interval \\
\hline \multicolumn{3}{|l|}{ Mood disorder } \\
\hline Lifetime BD & $0.6^{*}$ & 0.5 to 0.9 \\
\hline Lifetime MDD ${ }^{\dagger}$ (excluding BD) & 1.0 & - \\
\hline \multicolumn{3}{|l|}{ Sex } \\
\hline Males & $0.8^{*}$ & 0.6 to 1.0 \\
\hline Females $^{\dagger}$ & 1.0 & - \\
\hline \multicolumn{3}{|l|}{ Age group } \\
\hline 18 to 34 & 0.9 & 0.7 to 1.1 \\
\hline $35+^{+}$ & 1.0 & - \\
\hline \multicolumn{3}{|l|}{ Level of education } \\
\hline High school graduation or less ${ }^{\dagger}$ & 1.0 & - \\
\hline Some post-secondary education & $0.6^{*}$ & 0.4 to 0.9 \\
\hline Post-secondary graduation & 0.8 & 0.6 to 1.1 \\
\hline \multicolumn{3}{|l|}{ Comorbidity } \\
\hline Chronic condition present ${ }^{\S}$ & 0.9 & 0.7 to 1.2 \\
\hline \multicolumn{3}{|l|}{ Body mass index category } \\
\hline $\begin{array}{l}\text { Underweight/normal weight/ } \\
\text { overweight }(\mathrm{BMI}<30.0)^{\dagger}\end{array}$ & 1.0 & - \\
\hline Obese (BMI 30.0+) & 0.8 & 0.6 to 1.2 \\
\hline
\end{tabular}

${ }^{*}$ Estimate is significantly different from estimate for reference category $(p<0.05)$

${ }^{\dagger}$ Reference group, for which the odds ratio is always 1.0

- Not applicable

§ Reference group is absence of arthritis, asthma, back problems excluding fibromyalgia and arthritis, high blood pressure, migraine, chronic bronchitis, emphysema or COPD, diabetes, epilepsy, heart disease, cancer, stomach or intestinal ulcers, effects of a stroke, bowel disorder/Crohn's disease or colitis, Alzheimer's disease or other dementia, cataracts, glaucoma, and thyroid disorder.

Odds ratios have been rounded, some with 1.0 as the lower or upper confidence limit are statistically significant (as indicated).

Model is based on records of 2966 respondents screened positive for lifetime BD or MDD.

Source: 2002 Canadian Community Health Survey: Mental Health and Well-being

4. Kessler RC, Akiskal HS, Ames M, et al. Prevalence and effects of mood disorders on work performance in a nationally representative sample of U.S. workers. Am J Psychiatry 2006 September;163(9):1561-8.

5. Kennedy SH, Lam RW, Cohen NL, et al. Clinical guidelines for the treatment of depressive disorders. IV. Medications and other biological treatments. Can J Psychiatry 2001 June;46 Suppl 1:38S-58S.
6. Begley CE, Annegers JF, Swann AC, et al. The lifetime cost of bipolar disorder in the US: an estimate for new cases in 1998. Pharmacoeconomics 2001;19(5 Pt 1):483-95.

7. Greenberg PE, Kessler RC, Birnbaum HG, et al. The economic burden of depression in the United States: how did it change between 1990 and 2000? J Clin Psychiatry 2003 December;64(12):1465-75. 
8. Kessler RC, Akiskal HS, Ames M, et al. Considering the costs of bipolar depression. Behav Healthc 2007 January;27(1):45-7.

9. Judd LL, Akiskal HS. The prevalence and disability of bipolar spectrum disorders in the US population: re-analysis of the ECA database taking into account subthreshold cases. J Affect Disord 2003 January;73(1-2):123-31.

10. Dean BB, Gerner D, Gerner RH. A systematic review evaluating health-related quality of life, work impairment, and healthcare costs and utilization in bipolar disorder. Curr Med Res Opin 2004;20(2):139-54.

11. Akiskal HS, Bourgeois ML, Angst J, et al. Re-evaluating the prevalence of and diagnostic composition within the broad clinical spectrum of bipolar disorders. J Affect Disord 2000 September;59 Suppl 1: S5-S30.

12. Angst J, Gamma A, Benazzi F, et al. Toward a re-definition of subthreshold bipolarity: epidemiology and proposed criteria for bipolar-II, minor bipolar disorders and hypomania. J Affect Disord 2003 January;73(1-2):133-46.

13. Judd LL, Schettler PJ, Akiskal HS, et al. Long-term symptomatic status of bipolar I vs. bipolar II disorders. Int J Neuropsychopharmacol 2003 June;6(2):127-37.
14. Judd LL, Akiskal HS, Maser JD, et al. A prospective 12-year study of subsyndromal and syndromal depressive symptoms in unipolar major depressive disorders. Arch Gen Psychiatry 1998 August;55(8):694-700.

15. Judd LL, Akiskal HS. Depressive episodes and symptoms dominate the longitudinal course of bipolar disorder. Curr Psychiatry Rep 2003 December;5(6):417-8.

16. Judd LL, Akiskal HS, Schettler PJ, et al. The long-term natural history of the weekly symptomatic status of bipolar I disorder. Arch Gen Psychiatry 2002 June;59(6):530-7.

17. Judd LL, Akiskal HS, Schettler PJ, et al. Psychosocial disability in the course of bipolar I and II disorders: a prospective, comparative, longitudinal study. Arch Gen Psychiatry 2005 December; 62(12):1322-30.

18. Kessler RC, Berglund P, Demler O, et al. The epidemiology of major depressive disorder: results from the National Comorbidity Survey Replication (NCS-R). JAMA 2003 June 18;289(23):3095-105.

19. Katon WJ. Clinical and health services relationships between major depression, depressive symptoms, and general medical illness. Biol Psychiatry 2003 August 1;54(3):216-26.
20. Lin EH, Von Korff M, Ludman EJ, et al. Enhancing adherence to prevent depression relapse in primary care. Gen Hosp Psychiatry 2003 September;25(5):303-10.

21. Kessler RC, Rubinow DR, Holmes C, et al. The epidemiology of DSMIII-R bipolar I disorder in a general population survey. Psychol Med 1997 September;27(5):1079-89.

22. McIntyre RS, Konarski JZ, Soczynska JK, et al. Medical comorbidity in bipolar disorder: implications for functional outcomes and health service utilization. Psychiatr Serv 2006 August;57(8):1140-4.

23. McIntyre RS, Konarski JZ, Wilkins K, et al. The prevalence and impact of migraine headache in bipolar disorder: results from the Canadian Community Health Survey. Headache 2006 June;46(6):973-82.

24. McIntyre RS, Konarski JZ, Wilkins K, et al. Obesity in Bipolar Disorder and Major Depressive Disorder: Results from a National Community Health Survey on Mental Health and Well-Being. Can J Psychiatry 2006;51:274-80. 